\title{
Produção de pimentão em substratos e fertirrigação com efluente de biodigestor ${ }^{1}$
}

\author{
Thiago L. Factor ${ }^{2}$, Jairo A. C. de Araújo ${ }^{3}$ \& Luiz V. E. Vilella Júnior ${ }^{3}$ \\ RESUMO
}

O aproveitamento do efluente de biodigestor em fertirrigação e a utilização do esterco de suínos seco como componente do substrato, ao mesmo tempo em que diminuiriam o custo de produção da cultura do pimentão, evitariam o descarte desses resíduos no meio ambiente. Neste trabalho se objetivou avaliar a produtividade e a qualidade de frutos de pimentão vermelho híbrido 'Margarita' adotando-se o delineamento experimental fatorial 4 × 3 em blocos casualizados, sendo 4 substratos (S1, S2, S3 e S4) e 3 soluções nutritivas: solução nutritiva mineral (SN1), solução nutritiva à base de efluente de biodigestor, complementada com fertilizantes minerais (SN2) e solução nutritiva à base de efluente de biodigestor (SN3). A utilização das diferentes misturas que originaram os respectivos substratos, pode ser recomendada com boas perspectivas de produção e qualidade de frutos, com exceção do S1, que mostrou ser inferior aos demais, em termos de qualidade de frutos. A substituição parcial de fertilizantes minerais pelo efluente de biodigestor à base de dejetos de suínos, não foi suficiente para proporcionar produtividade equivalente à adubação $100 \%$ mineral; entretanto, alcançou padrões de qualidade semelhantes e com boa produtividade.

Palavras-chave: Capsicum annuum L., cultivo sem solo, dejeto de suínos, biofertilizante

\section{Pepper production in substrates using fertigation with biological reactor effluent}

\begin{abstract}
The use of biological reactor effluent in fertigation and use of dry swine waste as a component of the substrate, would lower the cost of production and prevent discarding residues in the environment. Based on that, the objective of this research was to evaluate both yield and quality of pepper fruits, adopting the factorial scheme $4 \times 3$ in randomized blocks, with 4 substrates (S1, S2, S3 e S4) and 3 nutrient solutions: mineral nutrient solution (SN1), nutrient solution as based on biological reactor effluent boosted with mineral fertilizers (SN2) and nutrient solution based on biological reactor effluent (SN3). The different mixtures that yielded different substrate could be recommended for both fruit and quality production perspectives, except substrate 1 (S1), which revealed inferior quality of fruits. The use of SN1 permitted greater weight of the fruits, thickness of the pulp and productivity. Partial substitution of fertilizers by biodigestor effluent of swine waste (SN2) was not sufficient to promote productivity equivalent to $100 \%$ mineral nutrient solution, however it reached mean index of productivity with standards of quality of fruits equivalent to the mineral solution (SN1). This supports the conclusion that the use of the biological reactor effluent would be an alternative in potential to reduce the cost of production of pepper crop and to prevent the discarding of this material, still rich in nutrients, into the environment.
\end{abstract}

Keywords: Capsicum annuum L., soiless crop, swine manure, biofertilizer

1 Parte da Dissertação de Mestrado do primeiro autor, Pós-Graduação em Agronomia, FCAV/UNESP, Campus de Jaboticabal

${ }^{2}$ Doutorando, Bolsista CNPq, DER/UNESP, Via de acesso Prof. Paulo D. Castellane s/n, CEP 14884-900, Jaboticabal, SP. Fone: (16) $3209-2637$. E-mail: factor@fcav.unesp.br

${ }^{3}$ FCAV/UNESP. Fone: (16) 3209-2637. E-mail: jaca@fcav.unesp.br 


\section{INTRODUÇÃO}

Nas últimas décadas, os aumentos marcantes de produtividade na agricultura moderna têm sido acompanhados, muitas vezes, pela degradação ambiental (poluição por pesticidas, erosão e salinização dos solos), problemas sociais (concentração de terras, recursos e produção, mudança no padrão de migração rural/urbana) e pelo uso excessivo dos recursos naturais. A produção agrícola moderna tornou-se altamente complexa, com ganhos de produção dependente de um manejo intensivo e de uma disponibilidade ininterrupta de energia e recursos suplementares.

As técnicas modernas utilizadas não são apropriadas a uma era pobre em energia e de perturbação ao ambiente sendo, assim, altamente coerente a busca de uma agricultura sustentável, conservadora dos recursos, eficiente no uso de energia e economicamente viável; em contrapartida, não se pode ignorar a necessidade de aumentar a produção e a qualidade dos produtos, obrigando o produtor a se tecnificar cada vez mais, adequando o seu produto e seus meios à demanda nacional.

Este aspecto se acentua, por certo, quando se trata especificamente da produção de hortaliças visto que, na maioria das vezes, o olericultor é um pequeno produtor e necessita retirar o máximo de rendimento de sua pequena propriedade; desta forma, a necessidade da tecnificação e otimização da produção surgem de maneira obrigatória, fazendo com que o produtor busque novos modelos de produção complementando, daí, o uso de técnicas e insumos convencionais com práticas de cunho ecológico garantindo uma produção agrícola mais acessível e sustentável.

Uma das técnicas da agricultura moderna que vêm sendo muito utilizadas para promover o cultivo fora de época, diminuir custos e aumentar a produtividade, é o cultivo protegido que, juntamente com as novas tecnologias aplicadas à área de irrigação, como a aplicação localizada, fertirrigação e, mais recentemente, a hidroponia, tem propiciado bons resultados.

Entre as culturas com importância econômica cultivada em ambiente protegido, o pimentão é uma alternativa. Segundo Melo (1997) é a cultura que melhor se tem adaptado ao ambiente protegido no estado de São Paulo. Lorentz et al. (2002) mencionam que das hortaliças cultivadas em ambiente protegido, o pimentão se situa entre as cinco culturas que apresentam maior área cultivada não só no Brasil mas em diversos países do mundo.

A maior parte dos cultivos protegidos, no entanto, é realizada utilizando-se o solo. Nos últimos tempos vários problemas vêm limitando o cultivo de hortaliças em solo. Segundo Andriolo (1997), dentre esses impasses se destacam: a incidência de pragas e os fitopatógenos que atacam o sistema radicular, como os nematóides e as podridões de raízes causadas por fungos e bactérias e, também, os de ordem nutricional, pois os elementos minerais não absorvidos pelas raízes das plantas tendem a se acumular no perfil do solo, provocando salinização e/ou antagonismo entre os nutrientes.

Com o decorrer do tempo, no entanto, só será possível o cultivo mediante o uso de tratamentos periódicos do solo, normalmente feito com brometo de metila, em que sua utilização ainda não é proibida porém o uso repetido do brometo pode causar sérios problemas de higiene e sanidade; além disso, existe a possibilidade de poluição das águas, do acúmulo de resíduos em frutos e intoxicação pelo homem (Calabreta et al., 1994).

Uma das alternativas atualmente existentes para contornar tais impasses e muito utilizada em países de agricultura moderna, é a utilização de substratos como suporte para as plantas, associados à técnica hidropônica em sistema aberto, em cuja prática se observa uma retenção maior de umidade e diminuição no consumo de energia elétrica, não havendo recirculação da solução nutritiva podendo-se, daí, evitar problemas com patógenos que atacam o sistema radicular das plantas.

Outra prática que pode oferecer redução dos custos de produção a um sistema hidropônico é a substituição ou diminuição do uso de fertilizantes minerais por fontes alternativas, mais econômicas como, por exemplo, o efluente de biodigestor (biofertilizante).

O interesse na utilização de resíduos orgânicos gerados no meio rural, se justifica não apenas pelos aspectos de reciclagem de nutrientes no próprio meio e aumento no rendimento das culturas mas, também, pelo aproveitamento de uma fonte renovável de energia, o biogás, podendo suprir, total ou parcialmente, as necessidades energéticas da propriedade rural (Lucas Júnior, 1994). Neste sentido, a utilização de nutrientes a partir do esterco de suínos após a fermentação em biodigestor, associada à técnica de cultivo hidropônico em substratos, é mais uma alternativa para reduzir custos, além de diminuir a extração das reservas naturais de nutrientes do planeta e melhor equacionar os problemas ligados à sanidade e salinização dos solos, contribuindo para a prática do saneamento ambiental e da sustentabilidade da propriedade agrícola.

Com vistas a tais questionamentos, realizou-se a presente pesquisa com o objetivo de estudar o comportamento da cultura do pimentão em condições de ambiente protegido, com uso da técnica hidropônica em diferentes substratos e do biofertilizante produzido a partir da fermentação anaeróbia de estrume de origem suína na composição da solução nutritiva e o dejeto de suíno seco, como componente dos diferentes substratos.

\section{MATERIAL E MÉTODOS}

O presente estudo foi conduzido no período de abril a setembro de 2003, em ambiente protegido, localizado em área experimental do Setor de Plasticultura do Departamento de Engenharia Rural, nas dependências da Faculdade de Ciências Agrárias e Veterinárias - UNESP, Campus de Jaboticabal, cujas coordenadas geográficas são $21^{\circ} 17^{\prime} 05^{\prime}$ S de Latitude e Longitude de $48^{\circ} 17^{\prime}$ 09” W. O clima de Jaboticabal, SP, é classificado como subtropical com chuvas de verão, inverno relativamente seco, com precipitação pluvial média de $1.400 \mathrm{~mm}$ anuais e temperatura média anual de $22,2{ }^{\circ} \mathrm{C}$, 
Tabela 1. Distribuição percentual dos componentes do substrato quanto ao diâmetro das partículas e densidade

\begin{tabular}{ccccccccc}
\hline \multirow{2}{*}{ Substrato } & Densidade & \multicolumn{7}{c}{ Diâmetro de Partículas $(\mathbf{m m})$} \\
\cline { 3 - 8 } & $\mathbf{( g ~ \mathbf { L } ^ { - 1 } )}$ & $\mathbf{<} \mathbf{0 , 1 2 5}$ & $\mathbf{0 , 1 2 5 - \mathbf { 0 , 2 5 }}$ & $\mathbf{0 , 2 5 - \mathbf { 0 , 5 }}$ & $\mathbf{0 , 5 - 1 , 0}$ & $\mathbf{1 , 0 - 2 , 0}$ & $\mathbf{2 , 0 - 4 , 0}$ & $>\mathbf{4 , 0}$ \\
S1 & $1169,17(1)$ & 3,88 & 9,77 & 33,45 & 26,77 & 16,27 & 6,64 & 3,21 \\
S2 & 1048,17 & 3,52 & 8,75 & 25,86 & 28,82 & 21,23 & 10,03 & 1,78 \\
S3 & 853,09 & 3,66 & 10,26 & 27,09 & 27,75 & 21,22 & 8,27 & 1,76 \\
S4 & 744,86 & 3,00 & 7,90 & 24,39 & 26,47 & 22,31 & 9,67 & 6,26 \\
\hline
\end{tabular}

(1) Resultados obtidos através de análise realizada no Laboratório de Solos e Adubos FCAV/UNESP, Jaboticabal, SP

temperatura máxima média anual de $28,9^{\circ} \mathrm{C}$ e mínima de 16,8 ${ }^{\circ} \mathrm{C}$ (Estação Agroclimatológica, 2003).

$\mathrm{O}$ ambiente protegido utilizado foi do tipo capela, com orientação Leste-Oeste no eixo de maior comprimento e inclinação de $22^{\circ}$ em relação à horizontal, construído em estrutura metálica, possuindo dimensões de $10 \mathrm{~m}$ de largura e $28 \mathrm{~m}$ de comprimento, totalizando uma área experimental de $280 \mathrm{~m}^{2}$ e altura do pé direito de $4 \mathrm{~m}$. Para cobertura da estrutura usou-se o filme de polietileno de baixa densidade (PEBD) transparente com espessura de 0,150 mm com aditivos ultravioleta e difusor de luz; nas laterais, tela de polipropileno preta com redução de $50 \%$ da radiação solar até aproximadamente $2 \mathrm{~m}$ de altura.

O delineamento experimental adotado foi o de blocos casualizados em esquema fatorial 4 x 3 com 4 repetições, composto de dois fatores: substratos e soluções nutritivas. A unidade experimental foi de $5,1 \mathrm{~m}^{2}$, contendo 15 plantas, no total de 60 plantas por tratamento e 720 plantas cultivadas. $\mathrm{O}$ fator substratos se compunha de 4 misturas de diferentes materiais associados: S1: 1/2 Areia (0,105-0,250 mm) + 1/2 Dejeto de suíno seco; S2: 1/3 Areia + 1/3 Casca de amendoim triturada $+1 / 3$ Dejeto de suíno seco; S3: 1/3 Areia $+1 / 3$ Casca de arroz carbonizada $+1 / 3$ Dejeto de suíno seco e S4: 1/4 Areia (0,105-0,250 mm) + 1/4 Casca de amendoim triturada $+1 / 4$ Casca de arroz carbonizada +1/4 Dejeto de suíno seco. As características físicas e químicas dos referidos substratos se encontram nas Tabelas 1 e 2, respectivamente.

Tabela 2. Características químicas iniciais dos substratos utilizados no experimento

\begin{tabular}{|c|c|c|c|c|}
\hline Características Avaliadas & S1 & s2 & S3 & $\$ 4$ \\
\hline $\mathrm{pH}$ em $\mathrm{H}_{2} \mathrm{O}$ & $7,04^{(1)}$ & 7,13 & 6,64 & 6,61 \\
\hline Condutividade $\left(\mathrm{dS} \mathrm{m}^{-1}\right)$ & 4,28 & 2,99 & 3,14 & 3,00 \\
\hline$N\left(m g ~ L^{-1}\right)$ & 155,01 & 177,76 & 138,1 & 128,30 \\
\hline$P\left(m g L^{-1}\right)$ & 60,52 & 57,43 & 36,43 & 36,07 \\
\hline $\mathrm{K}\left(\mathrm{mg} \mathrm{L}^{-1}\right)$ & 730,63 & 592,06 & 642,45 & 629,85 \\
\hline $\mathrm{Ca}\left(\mathrm{mg} \mathrm{L}^{-1}\right)$ & 38,46 & 36,47 & 52,44 & 54,69 \\
\hline$M g\left(\mathrm{mg} \mathrm{L}^{-1}\right)$ & 62,33 & 45,45 & 60,17 & 61,96 \\
\hline$S\left(\mathrm{mg} \mathrm{L}^{-1}\right)$ & 110,32 & 58,40 & 53,26 & 50,94 \\
\hline $\mathrm{Zn}\left(\mathrm{mg} \mathrm{L}^{-1}\right)$ & 0,13 & 0,17 & 0,10 & 0,10 \\
\hline $\mathrm{Fe}\left(\mathrm{mg} \mathrm{L}^{-1}\right)$ & 1,09 & 2,21 & 0,53 & 0,44 \\
\hline$M n\left(m g ~ L^{-1}\right)$ & 0,20 & 0,21 & 0,66 & 0,57 \\
\hline$B\left(m g L^{-1}\right)$ & 0,32 & 0,30 & 0,24 & 0,18 \\
\hline $\mathrm{Cu}\left(\mathrm{mg} \mathrm{L}^{-1}\right)$ & 1,0 & 1,02 & 0,25 & 0,19 \\
\hline $\mathrm{Na}\left(\mathrm{mg} \mathrm{L}^{-1}\right)$ & 293,58 & 117,43 & 97,86 & 90,54 \\
\hline $\mathrm{Cl}\left(\mathrm{mg} \mathrm{L}^{-1}\right)$ & 13,8 & 6,22 & 5,71 & 5,47 \\
\hline
\end{tabular}

(1) Resultados obtidos através de análise realizada no Laboratório de Solo e Substratos do Instituto Agronômico de Campinas, adotando-se o método de extrato aquoso 1:1,5 ( $\left.\mathrm{v} \mathrm{v}^{-1}\right)$, Campinas, SP
Já o fator tipos de soluções nutritivas, foi formado por três diferentes soluções: solução nutritiva, formulada a partir de fertilizante mineral (SN1), segundo recomendações de Castellane \& Araújo (1994) com as seguintes concentrações totais de nutrientes em mg L-1: 152, 39, 245, 110, 29, 32, 3,7, 0,3, 0,4, 0,3, 0,05 e 0,05 para N, P, K, Ca, Mg, S, Fe, Zn, $\mathrm{Mn}, \mathrm{B}, \mathrm{Cu}$ e Mo, respectivamente; solução nutritiva formulada à base de efluente de biodigestor (biofertilizante), complementada com fertilizantes minerais (SN2), de forma a constituir uma solução nutritiva com concentrações de nutrientes próximas às recomendadas por Castellane \& Araújo (1994), obtendo-se a seguinte concentração de nutrientes em mg L-1: 159,5, 54, 245, 110, 29, 32, 3,7, 0,34, 0,4, 0,4, 0,1, 0,05 e 18,0 para N, P, K, Ca, Mg, S, Fe, Zn, Mn, B, Cu, Mo e Na, respectivamente; e solução nutritiva à base de efluente de biodigestor (SN3), sem complementação com fertilizantes minerais, com a seguinte concentração de nutrientes em $\mathrm{mg} \mathrm{L}^{-1}$ : 140, 54, 48, 65, 26, 20, 1,4, 0,20, 0,40, 0,40, 0,1 e 18 para N, P, K, Ca, Mg, S, Fe, Zn, Mn, B, Cu e Na, respectivamente.

O efluente de biodigestor utilizado na presente pesquisa foi resultado da fermentação anaeróbia sofrida pelo estrume de suíno, obtido através da limpeza das instalações desses animais em criação intensiva, nas fases de crescimento e terminação, em biodigestor de fluxo ascendente com leito de lodo (UASB), operando com tempo de retenção de 14,7 h e teor de sólidos suspensos totais de $2 \mathrm{~g} \mathrm{~L}^{-1}$.

O cultivo do pimentão foi realizado em regime de hidroponia aberta (sem circulação da solução nutritiva) e em sacos de polietileno preto, com 0,10 mm de espessura, 0,30 m de diâmetro e $0,25 \mathrm{~m}$ de altura, preenchidos com $20 \mathrm{dm}^{3}$ de substrato. Os recipientes contendo uma muda de pimentão foram dispostos em fileiras duplas, no espaçamento de $1,10 \times 0,60 \times 0,40$, sendo $0,40 \mathrm{~m}$ entre recipientes, $0,60 \mathrm{~m}$ entre fileiras simples e 1,10 m entre fileiras duplas, com densidade de 2,94 plantas por $\mathrm{m}^{2}$.

Para o acondicionamento dos sacos em fileiras duplas foram construídos pequenos canteiros de $0,90 \mathrm{~m}$ de largura e $0,20 \mathrm{~m}$ de altura, cobertos com filme plástico preto de 0,10 mm, em cuja parte central se construíram canais (canaletas) com pequena declividade $(0,5 \%)$, visando promover o escoamento da solução drenada e, com isto, diminuir a umidade e concentração de sais nos substratos.

O híbrido utilizado foi o 'Margarita', tipo verde/vermelho e recomendado para o cultivo em ambiente protegido, enquanto as mudas foram formadas em bandejas de poliestireno expandido com capacidade para 128 células piramidais e a semeadura realizada no dia 03/04/03, colocando-se uma semente por célula. O transplantio ocorreu aos 36 dias 
após a semeadura, em 09/05/03, quando as plântulas apresentavam de 2 a 3 folhas definitivas e aproximadamente $12 \mathrm{~cm}$ de altura.

As plantas foram conduzidas com 4 hastes principais e tutoradas de forma individual sendo que, abaixo da primeira bifurcação, foram retirados todos os brotos laterais e a flor que surgiu na primeira bifurcação.

O método de irrigação adotado foi o localizado, do tipo gotejamento, com emissores com vazão de 2,8 $\mathrm{L} \mathrm{h}^{-1}$ a pressão de serviço de $70 \mathrm{Kpa}$, sendo colocado um emissor em cada recipiente. O manejo da irrigação foi realizado a partir dos valores de consumo de água diário pela cultura, medido em mini-lisímetro de pesagem com dimensões de 0,30 m de diâmetro e $0,25 \mathrm{~m}$ de altura para o cilindro interno e $0,34 \mathrm{~m}$ e 0,45 m para o cilindro externo acoplados a um sistema de aquisição de dados "Datalloger" e os valores registrados convertidos em mL de água por planta através de equação de calibração, adotando-se uma freqüência diária de fertirrigação.

Na primeira semana após o transplantio se aplicou somente água, sem adição de fertilizantes orgânicos ou minerais; a partir da segunda semana, foi aplicada uma solução contendo $50 \%$ das concentrações de nutrientes preestabelecidas e, a partir da terceira semana, $100 \%$ das concentrações de nutrientes, de forma a promover o pegamento e aclimatização das mudas em seu local definitivo.

Em relação às características de produção, foram analisados: a) peso médio dos frutos: obtido com o auxílio de uma balança digital, marca Marte, modelo AS 2000, com precisão de centésimo de grama; b) espessura da polpa: média de três medidas efetuadas no terço médio dos frutos com paquímetro digital Digimatic, marca Mitutoyo, modelo CD 6”, série 500, com precisão de 0,1 mm; c) número de frutos por planta: por contagem manual e d) produtividade total.

Avaliaram-se, nos frutos, as características químicas: a) sólidos solúveis totais: determinados por refratometria, com refratômetro portátil ATC da marca Átago e os resultados expressos em ${ }^{\circ}$ Brix; b) acidez total titulável: segundo a técnica de titulação com hidróxido de sódio $(\mathrm{NaOH})$ a $0,1 \mathrm{~N}$, de acordo com metodologia recomendada pelo Instituto Adolfo Lutz (1985); c) pH: com o auxílio de um peagâmetro portátil da marca Oaklon e d) vitamina C: obtida pelo método de redução do iodo, conforme metodologia recomendada pelo Instituto Adolfo Lutz (1985).

A colheita dos frutos foi individualizada e nas 10 plantas centrais de cada parcela experimental, realizada semanalmente, quando os frutos atingissem em torno de $70 \%$ de coloração vermelha, sendo que o início da colheita ocorreu no dia 12/08/03 e o término em 26/09/03, no total de 7 semanas.

Para classificação dos frutos foram levados em consideração o grupo, subgrupo, classe, subclasse e categoria sendo que, nesta última etapa, fez-se a caracterização e a quantificação dos defeitos considerados graves e leves, obedecendose aos limites de tolerância para cada tipo de defeito, permitindo a distinção em Extra, Categoria I, Categoria II e Categoria III, conforme programa paulista para melhoria dos padrões comerciais e embalagens de hortifrutigranjeiros (São Paulo, 1998).

\section{RESULTADOS E DISCUSSÃO}

Não se verificou diferenças significativas entre substratos, soluções nutritivas e da interação substratos x soluções nutritivas sobre sólidos solúveis totais (S.S.T), acidez total titulável (A.T.T) e potencial hidrogeniônico $(\mathrm{pH})$ (Tabela 3).

Os valores médios de vitamina C (Vit.C), mostraram haver diferenças significativas apenas entre as soluções nutritivas, não ocorrendo diferenças para a interação substratos $\mathrm{x}$ soluções nutritivas nem entre substratos.

Os frutos colhidos nos tratamentos com solução nutritiva à base de efluente de biodigestor (SN3), apresentaram maiores teores de Vit. C (184,08 mg $\left.100 \mathrm{~g}^{-1}\right)$, não diferindo significativamente dos tratamentos com solução à base de efluente, complementada com fertilizante mineral (SN2) (178,08 mg $100 \mathrm{~g}^{-1}$ ). Os menores valores foram observados quando se utilizou a solução mineral (SN1) como aporte nutricional indicando, em média (171,08 mg $\left.100 \mathrm{~g}^{-1}\right)$, diferindo significativamente apenas da SN3 (Tabela 3).

Os teores de Vit. C constatados neste trabalho foram bastante superiores aos encontrados por Damatto Júnior et al. (2000) para o híbrido 'Zarco', sob ambiente protegido, que variaram de $82,96 \mathrm{mg} 100 \mathrm{~g}^{-1}$ a $111,51 \mathrm{mg} 100 \mathrm{~g}^{-1}$ e Yahia et al. (2002) que, estudando o comportamento da Vit. C em frutos de pimentão cv. 'New Ace' ao longo do desenvolvimento, maturação e senescência, obtiveram valores máximos de $136 \mathrm{mg} 100 \mathrm{~g}^{-1}$, cerca de 51 dias após o pegamento dos frutos; entretanto, os valores de Vit. C observados neste trabalho se encontram em faixa considerada adequada, variando de 150 a $180 \mathrm{mg} 100 \mathrm{~g}^{-1}$ para frutos maduros, segundo Pádua (1981) e Reifschneider (2000).

O emprego dos diferentes substratos não interferiu no peso médio dos frutos; para esta característica analisada não se

Tabela 3. Sólidos Solúveis Totais (SST), Acidez Total Titulável (ATT), Potencial Hidrogeniônico $(\mathrm{pH})$ e Vitamina C (Vit. C) em função de diferentes tipos de soluções nutritivas e substratos

\begin{tabular}{|c|c|c|c|c|}
\hline \multirow[b]{2}{*}{ Tratamentos } & \multicolumn{4}{|c|}{ Características Tecnológicas dos frutos } \\
\hline & $\begin{array}{l}\text { SST } \\
\text { ("brix) }\end{array}$ & $\begin{array}{c}\text { ATT } \\
\left(\mathrm{g} 100 \mathrm{~g}^{-1}\right)\end{array}$ & $\mathrm{pH}$ & $\begin{array}{c}\text { Vit.C } \\
\left(m g 100 g^{-1}\right)\end{array}$ \\
\hline \multicolumn{5}{|l|}{ Substratos } \\
\hline S1 & $6,59^{(1)}$ & 0,16 & 5,04 & 170,18 \\
\hline S2 & 7,52 & 0,17 & 4,98 & 184,46 \\
\hline S3 & 7,25 & 0,15 & 4,95 & 178,42 \\
\hline S4 & 7,06 & 0,16 & 5,03 & 178,62 \\
\hline Teste F & $1,86^{\mathrm{ns}}$ & $1,85^{\mathrm{ns}}$ & $1,56 \mathrm{~ns}$ & $2,44^{\mathrm{ns}}$ \\
\hline dms $(5 \%)$ & 1,09 & 0,024 & 0,12 & 14,39 \\
\hline \multicolumn{5}{|c|}{ Soluções Nutritivas ${ }^{(1)}$} \\
\hline SN1 & 7,19 & 0,16 & 5,03 & $171,08 \mathrm{~b}$ \\
\hline SN2 & 6,82 & 0,15 & 4,98 & $178,08 \mathrm{ab}$ \\
\hline SN3 & 7,30 & 0,16 & 4,98 & 184,61 a \\
\hline Teste F & $1,01^{\mathrm{ns}}$ & $0,53^{\mathrm{ns}}$ & 1,23 ns & 4,31 * \\
\hline dms (5\%) & 0,86 & 0,018 & 0,09 & 11,94 \\
\hline Interação S x SN & $0,87 \mathrm{~ns}$ & $0,35^{\mathrm{ns}}$ & $1,99 \mathrm{~ns}$ & $1,81^{\text {ns }}$ \\
\hline C.V. $(\%)$ & 13,92 & 13,50 & 2,17 & 7,78 \\
\hline
\end{tabular}

(1) Médias na coluna seguidas da mesma letra não diferem estatisticamente entre si pelo teste Tukey a $5 \%$; * Significativo a nível de $5 \%$ de probabilidade; ** Significativo a nível de $1 \%$ de probabilidade; ns Não significativo 
verificaram diferenças significativas entre substratos e para a interação substratos x soluções nutritivas; no entanto, podese constatar diferenças significativas em relação às soluções nutritivas (Tabela 4).

Nota-se que os frutos colhidos nas parcelas referentes à SN1 apresentaram os maiores valores de peso médio $(178,45$ g) quando comparadas com as demais soluções nutritivas, não diferindo, porém, significativamente, da solução SN2 (178,08 g) que, por sua vez, não diferiu da solução SN3, na qual se observou menor valor (166,34 g), apresentando-se significativamente inferior a SN1.

Esses resultados corroboram com os obtidos por Ribeiro et al. (2000) que, trabalhando com adubação orgânica em pimentão cv. 'Nacional AG 506', obtiveram aumentos significativos no peso médio do fruto quando utilizaram fontes orgânicas e orgânicas + minerais, com destaque para a adubação organo-mineral com a associação de vermicomposto + adubação química. Por outro lado, Horino et al. (1986) que obtiveram resposta linear significativa no aumento do peso dos frutos quando doses de fertilizantes minerais foram adicionadas na presença de adubos orgânicos.

Tabela 4. Peso médio dos frutos (PMF), espessura da polpa dos frutos (EPF), número de frutos por planta (NFP) e produtividade em função de diferentes tipos de soluções nutritivas e substratos

\begin{tabular}{|c|c|c|c|c|}
\hline \multirow[b]{2}{*}{ Tratamentos } & \multicolumn{4}{|c|}{ Características de Produção } \\
\hline & $\begin{array}{l}\text { PMF } \\
\text { (g) }\end{array}$ & $\begin{array}{l}\text { EPF } \\
\text { (cm) }\end{array}$ & NFP & $\begin{array}{l}\text { Produtividade } \\
\left(\mathrm{kg} \mathrm{m}^{-2}\right)\end{array}$ \\
\hline \multicolumn{5}{|l|}{ Substratos } \\
\hline S1 & $172,48^{(1)}$ & $0,55 \mathrm{a}$ & 10,30 & 5,50 \\
\hline S2 & 167,51 & $0,51 \mathrm{~b}$ & 10,08 & 5,30 \\
\hline S3 & 166,49 & $0,53 a b$ & 10,73 & 5,51 \\
\hline \$4 & 179,96 & $0,54 \mathrm{a}$ & 9,94 & 5,38 \\
\hline Teste F & 2,65 ns & $6,45 * *$ & $0,43^{\text {ns }}$ & $0,15^{\mathrm{ns}}$ \\
\hline dms $(5 \%)$ & 14,45 & 0,27 & 2,00 & 0,98 \\
\hline \multicolumn{5}{|c|}{ Soluções Nutritivas ${ }^{(1)}$} \\
\hline SN1 & $178,45 \mathrm{a}$ & $0,55 \mathrm{a}$ & 10,89 & $6,02 \mathrm{a}$ \\
\hline SN2 & $170,03 a b$ & $0,54 \mathrm{a}$ & 9,62 & $4,99 \mathrm{~b}$ \\
\hline SN3 & $166,34 \mathrm{~b}$ & $0,50 \mathrm{~b}$ & 10,27 & $5,25 \mathrm{~b}$ \\
\hline Teste F & 3,60 * & 18,16 ** & $1,96 \mathrm{~ns}$ & 5,87 ** \\
\hline dms $(5 \%)$ & 11,35 & 0,21 & 1,57 & 0,77 \\
\hline Interação S x SN & $0,34^{\mathrm{ns}}$ & $1,44 \mathrm{~ns}$ & $0,88 \mathrm{~ns}$ & $3,96^{\mathrm{ns}}$ \\
\hline C.V. $(\%)$ & 7,62 & 4,60 & 17,65 & 16,39 \\
\hline
\end{tabular}

(1) Médias na coluna seguidas da mesma letra não diferem estatisticamente entre si pelo teste Tukey a $5 \%$; * Significativo a nível de $5 \%$ de probabilidade; ${ }^{*}$ Significativo a nível de $1 \%$ de probabilidade; ns Não significativo

Os valores médios para espessura da polpa dos frutos (E.P.F) indicaram diferenças significativas entre substratos e soluções nutritivas (Tabela 4). A comparação entre as médias aponta que os frutos colhidos das plantas conduzidas no S1 apresentaram os maiores valores $(0,55 \mathrm{~cm})$, seguidos de S4 $(0,54 \mathrm{~cm})$ e S3 $(0,53 \mathrm{~cm})$; entretanto, não se verificaram diferenças significativas entre os mesmos; o S2 proporcionou a formação de frutos com menores valores médios para esta característica analisada, em torno de $0,51 \mathrm{~cm}$, não diferindo significativamente apenas do S3.

Para o fator soluções nutritivas a SN3 indicou o menor valor $(0,50 \mathrm{~cm})$ diferindo significativamente da SN1
$(0,55 \mathrm{~cm})$ e SN2 $(0,54 \mathrm{~cm})$, não se detectando diferenças significativas entre essas duas últimas soluções, em termos de espessura média da casca dos frutos.

Os resultados aqui obtidos foram inferiores aos de Cunha (2001), cultivando o híbrido 'Elisa' em ambiente protegido com valores médios de 0,67 cm e semelhantes aos verificados por Scivittaro et al. (1999) caracterizando híbridos de pimentão vermelho para o cultivo protegido, com uso de adubação orgânica de base e fertirrigação, encontrando valores de espessura de polpa da ordem de 0,53, 0,57, 0,54 e 0,56 cm para os híbridos 'Luis', 'Fresco', 'Jucal' e 'HXP14187', respectivamente.

Para o caráter número médio de frutos por planta, verificou-se não ter sido alterado em função dos diferentes substratos, tipos de soluções nutritivas e interação substratos $\mathrm{x}$ soluções nutritivas a nível de 5\% de significância (Tabela 4); já para produtividade houve efeito significativo apenas para os tipos de solução nutritiva, independente dos substratos, sendo que as plantas conduzidas com a utilização das soluções organo-mineral (SN2) e orgânica (SN3) apresentaram os menores valores $4,99 \mathrm{~kg} \mathrm{~m}^{-2}$ e $5,25 \mathrm{~kg} \mathrm{~m}^{-2}$, respectivamente, não mostrando, no entanto, diferenças entre si; observouse, todavia, que a solução mineral (SN1) foi significativamente superior às demais, apresentando produtividade média total da ordem de $6,02 \mathrm{~kg} \mathrm{~m}^{-2}$, cujos resultados concordam com Ribeiro et al. (2000) que obtiveram ganho adicional de 3,5 tha-1 ${ }^{-1}$ quando efetuaram a aplicação de apenas adubo orgânico na ausência do mineral em relação à testemunha, enquanto na presença de fertilizantes minerais este ganho adicional foi de 7,0 $\mathrm{t} \mathrm{ha}^{-1}$.

Quando se utilizou integralmente (SN3) ou parcialmente (SN2) o efluente de biodigestor, se obteve uma produtividade menor, atribuída ao desbalanço e déficit de nutrientes como possível causa do menor rendimento da solução SN3; já o rendimento inferior obtido pela solução SN2 que apresentava, em tese, concentrações de nutrientes próximas à solução SN1, pode estar relacionado a uma possível reação de antagonismo e complexação dos nutrientes pelas partículas orgânicas em suspensão.

A aplicação de alguns quelatos orgânicos como, por exemplo, o EDTA, que nada mais são que ácidos orgânicos, provocou antagonismo com outros nutrientes (Cull, 1981) e toxicidade em plantas (van Driel, 1964, apud Rodrigues, 2002).

Existe, ainda, a possibilidade de produção de substâncias fitotóxicas pelos microrganismos na solução nutritiva, como os compostos fenólicos, aldeídos aromáticos, sulfuretos de hidrogênio e outros (Rodrigues, 2002). Toshiki (1999) estudou o efeito de compostos fenólicos na produção de mudas de pepino em hidroponia. Os ácidos benzóico, p-hidroxibenzóico e o fitálico indicaram efeito inibidor no crescimento; entretanto, quando foi adicionado carvão ativado à solução nutritiva, o efeito inibidor dos compostos fenólicos foi neutralizado.

Novas pesquisas com a interação de nutrientes minerais e efluentes de biodigestores, bem como formas de tratamento do efluente para uso em solução nutritiva, devem ser desenvolvidas no sentido de melhor esclarecer a dinâmica de nutrientes neste material. 
Os rendimentos médios obtidos nesta pesquisa superam os de Pedro \& Vicente (1988) com 4,0 $\mathrm{kg} \mathrm{m}^{-2}$ para o cultivo de inverno na Espanha, Faria Júnior (1997) 4,0 kg m², utilizando o híbrido 'Magali', em estufa do tipo capela, na região de Jaboticabal, e os de Ribeiro et al. (2000) que obtiveram 2,0 kg m-2 como melhor produtividade com associação de adubação química e orgânica, porém Cunha (2001) encontrou valores bastante superiores, da ordem de $9,96 \mathrm{~kg} \mathrm{~m}^{-2}$, trabalhando com o híbrido 'Elisa' em ambiente protegido.

Segundo Cunha (2001) é muito difícil a comparação de produção entre as diversas pesquisas realizadas com a cultura do pimentão em ambiente protegido, em virtude dos mais variados conceitos utilizados pelos autores. Neste sentido, Fontes (1997) sugere que nessas pesquisas sejam obtidas as produtividades levando-se em consideração a classificação dos frutos, além do tempo entre a semeadura e a última colheita.

Para classificação dos frutos, foram levados em consideração o grupo, subgrupo, classe, subclasse e categoria, conforme recomendações de São Paulo (1998), verificando-se que o grupo predominante neste trabalho foi o retangular apresentando, como subgrupo, o vermelho.

Com relação à classe e subclasse, obtidas através das medidas de comprimento e diâmetro, os frutos referentes à solução orgânica (SN3) apresentaram classificação 8 e 4, inferior às obtidas para as soluções SN1 e SN2, com valores de 10 e 6 para classe e subclasse, respectivamente; para o fator substratos não houve classificação diferenciada, enquadrando-se todos os tratamentos na classe 10 e subclasse 6 de frutos.

Por intermédio da Tabela 5, que traz a classificação dos frutos segundo a categoria, pode-se observar que, dentre os substratos utilizados, apenas o S1 apresentou, como categoria de frutos, a II, considerada inferior às categorias obtidas para os demais substratos, que se mostraram como Extra.

A classificação inferior dos frutos, em termos de categoria obtida pelo $\mathrm{S} 1$, pode estar relacionada ao alto valor de condutividade elétrica inicial (Tabela 2), em conseqüência dos altos níveis de $\mathrm{Na}$ e $\mathrm{K}$, principalmente pelo fato de que ao longo do ciclo da cultura poderiam estar competindo com os cátions Ca e Mg pelos sítios de absorção, os quais desempenham funções específicas no desenvolvimento das plantas e formação dos frutos.

O cálcio está relacionado à elongação e divisão celular; além disso, possui função estrutural na parede celular, através dos pectatos de cálcio. O Mg participa da formação de açúcares, óleos, gorduras e como cofator de várias enzimas (Rodrigues, 2002) estando, portanto, diretamente relacionado com a qualidade dos frutos.

Segundo Loures et al. (1998) há uma estreita relação entre o crescimento das plantas e a pressão osmótica da solução do solo ou substrato, inteiramente dependente da concentração total de sais existentes e ressalta, ainda, que a presença de quantidades excessivas de sais restringe a absorção de água e de nutrientes e, conseqüentemente, a produtividade e qualidade de frutos. Furlani et al. (1999) recomendam que a solução nutritiva para o cultivo do pimentão deve situar-se na faixa de 2,0 a 3,0 dS m $\mathrm{m}^{-1}$ para o bom desenvolvimento e produção da cultura.
De maneira geral e à exceção do S1, os resultados apresentados para os diferentes substratos são importantes para produção comercial de pimentão, uma vez que mostram que materiais de baixo custo, como a palha de arroz, casca de amendoim e o esterco seco de suínos, se constituem alternativas viáveis na elaboração e uso como substrato, uma vez que proporcionaram condições satisfatórias para um bom desenvolvimento, produção e qualidade de frutos.

A casca de amendoim é um subproduto abundante da agroindústria canavieira, que utiliza a cultura do amendoim em rotação com a cana-de-açúcar. A palha de arroz pode ser facilmente encontrada a preços relativamente baixos em indústrias de beneficiamento de arroz e o esterco de suínos, ao longo dos anos, se torna um problema ambiental em criações intensivas, necessitando de acompanhamento integral para o descarte racional desses resíduos.

Tabela 5. Classificação de pimentões 'híbrido Margarita' em categorias, de acordo com a qualidade dos frutos e em função de diferentes tipos de soluções nutritivas e substratos

\begin{tabular}{ccccc}
\hline \multirow{2}{*}{ Substratos } & \multicolumn{3}{c}{ Soluções Nutritivas } & \multirow{2}{*}{ Média } \\
\cline { 2 - 4 } & SN1 & SN2 & SN3 & \\
S1 & I & II & III & II \\
S2 & Extra & Extra & II & Extra \\
S3 & Extra & Extra & III & Extra \\
S4 & Extra & Extra & III & Extra \\
Média & Extra & Extra & III & \\
\hline
\end{tabular}

\section{CONCLUSÕES}

1. Os substratos compostos de: $1 / 3$ areia $+1 / 3$ casca de amendoim triturada $+1 / 3$ dejeto de suíno seco, $1 / 3$ areia $+1 / 3$ casca de arroz carbonizada $+1 / 3$ dejeto de suíno seco e $1 / 4$ areia $+1 / 4$ casca de amendoim triturada $+1 / 4$ casca de arroz carbonizada $+1 / 4$ dejeto de suíno seco, proporcionaram condições satisfatórias para o bom desenvolvimento, produção e qualidade de frutos de pimentão.

2. A substituição parcial de fertilizantes minerais pelo efluente de biodigestor, à base de dejetos de suínos, não foi suficiente para proporcionar produtividade equivalente à adubação $100 \%$ mineral; entretanto, alcançou padrões de qualidade semelhantes e com boa produtividade.

3. O uso do efluente de biodigestor à base de dejetos de suínos pode ser considerado uma alternativa em potencial para reduzir os custos de produção no cultivo em substratos e, principalmente, evitar o descarte deste material ainda rico em nutrientes no meio ambiente.

\section{AgRADECIMENTOS}

Os autores agradecem à FAPESP (Fundação de Amparo à Pesquisa do Estado de São Paulo) pelos recursos de auxílio à pesquisa concedidos (Processo 01/06459-8), tornando possível a realização deste trabalho. 


\section{LITERATURA CITADA}

Andriolo, J. L.; Duarte, T. S.; Ludke, L.; Skrebsky, E. C. Crescimento e desenvolvimento do tomateiro cultivado em substrato com fertirrigação. Horticultura Brasileira, v.15, n.1, p.28-32, 1997.

Calabreta, C.; Nucifora, M. T.; Ferro, O. B. New techniques for the cultivation and defence of tomato crops in cold greenhouses in the area Regusa. Acta Horticulturae, n.361, p.530-544, 1994.

Castellane, P. D.; Araújo, J. A. C de. Cultivo sem solo: Hidroponia. Jaboticabal: FUNEP, 1994, 43p.

Cull, D. C. Nutrient film technique: Iron nutrient of swett pepper in relation to root temperature. Acta Horticulture, v.126, p.397407, 1981.

Cunha, A. R. Parâmetros agrometeorológicos de cultura de pimentão (Capsicum annuum L.) em ambientes protegido e campo. Botucatu: UNESP, 2001. 128p. Tese Doutorado

Damatto Júnior, E. R.; Rodrigues, D. S.; Vicentini, N. M.; Goto, R. Qualidade pós-colheita de frutos de pimentão amarelo sob diferentes lâminas de água e cobertura do solo. Horticultura Brasileira, v.18, n.1, p.206-208, 2000. Suplemento 2.

Estação Agroclimatológica. Resenha meteorológica no período, 19712000. Jaboticabal: UNESP/FCAV, 2003. http://www.fcav.unesp.br/ departamentos/exatas/estação/ resenha.html. 13 Out. 2005.

Faria Júnior, M. J. A. Avaliação de diferentes arquiteturas de estufas, coberturas do solo com filme plástico, em híbridos de pimentão (Capsicum annum L.). Jaboticabal: FCAV/UNESP, 1997. 102p. Tese Doutorado

Fontes, P. C. R. Produtividade do tomateiro: $\mathrm{kg} \mathrm{ha}^{-1}$ ou kg ha-1 $\mathrm{dia}^{-1}$. Horticultura Brasileira, v.15, n.2, p.83-4, 1997.

Furlani, P. R.; Silveira, L. C. P.; Bolonhezi, D.; Faquin, N. Cultivo hidropônico de plantas. Campinas: Instituo Agronômico, 1999. 52p. Documentos IAC

Horino, Y.; Lima, J. A.; Cordeiro, C. M. T.; Rossi, P. E. Influência da matéria orgânica e níveis de fósforo na produção de pimentão. Horticultura Brasileira, v.4, n.1, p.58, 1986.

Instituto Adolf Lutz. Normas analíticas do Instituto Adolfo Lutz: Métodos químicos e físicos para análise de alimentos. 3.ed. São Paulo: Instituto Adolf Lutz, 1985. v.1, p.392-395.

Lorentz, L. H.; Lúcio, A. D.; Heldwein, A. B.; Souza, M. F.; Mello, R. M. Estimativa da amostragem para pimentão em estufa plástica. Horticultura Brasileira, v.20, n.2, 2002. Suplemento 2. CD Rom
Loures, J. L.; Fontes, P. C. R.; Sediyama, M. A. N.; Casali, V. W. D.; Cardoso, A. A. Produção e teores de nutrientes no tomateiro cultivado em substrato contendo esterco de suínos. Horticultura Brasileira, v.16, n.1, p.50-55, 1998.

Lucas Júnior, J. Algumas considerações sobre o estrume de suínos, como substrato para três sistemas de biodigestores anaeróbios. Jaboticabal: FCAV/UNESP. 1994.137p. Tese Livre Docência

Melo, A. M. T. Análise genética de caracteres de frutos em híbridos de pimentão. Piracicaba. ESALQ/USP, 1997. 112p. Tese Doutorado

Pádua, J. G. de. Nutrição mineral do pimentão (Capsicum annuum L.). In: Casali, V. W. D. Seminários de olericultura. Viçosa: UFV, v.2, 1981, p.256-285.

Pedro, F. R.; Vicente, L. M. M. Alicación de los plásticos em la agricultura. 2.ed., Madri: Mundi-Prensa, 1988, 573p.

Reifschneider, F. J. B. Capsicum. Pimentas e pimentões no Brasil. Brasília: Embrapa Comunicação para Transferência de Tecnologia, Embrapa Hortaliças, 2000, 113p.

Ribeiro, L. G.; Lopes, J. C.; Martins Filho, S.; Ramalho, S.S. Adubação orgânica na produção de pimentão. Horticultura Brasileira, v.18, n.2, p.134-137, 2000.

Rodrigues, L. F. R. Técnicas de cultivo hidropônico e de controle ambiental no manejo de pragas, doenças e nutrição vegetal em ambiente protegido. Jaboticabal: FUNEP, 2002, 762p.

São Paulo. Secretaria de Agricultura e Abastecimento. Programa paulista para melhoria dos padrões comerciais e embalagens de hortifrutigranjeiros. Classificação de pimentão. São Paulo, 1998. s.p. (folheto).

Scivittaro, W. B.; Mello, A. M. T.; Tavares, M.; Azevedo Filho, J. A. de; Carvalho, C. R. L.; Ramos, M. T. B. Caracterização de híbridos de pimentão em cultivo protegido. Horticultura Brasileira, v.17, n.2, p.147-150, 1999.

Toshiki, A. Influences of phenolics isolated from the nutrient solution nourishing geowing cucumber (Cucumis sativus L.) plants on fruit yield. Journal Japonese Society Horticultural Science, v.68, n.4, p.847-53, 1999.

Yahia, E. M.; Contreras-Padilha, M.; Gonzales-Aguiar, G. Ascorbic acid content in relation to ascorbic acid oxidase activity and polyamine content in tomato and bell pepper fruits during development, maturation and senescence. Lebensm.-Wiss. u-Tecnol, v.34, p.452-457. http://www.idealibrary.com. 20 Dez. 2002. 